\title{
Clinical and radiological characteristics of lung disease in inflammatory bowel disease
}

\author{
R. Mahadeva*, G. Walsh**, C.D.R. Flower**, J.M. Shneerson*
}

Clinical and radiological characteristics of lung disease in inflammatory bowel disease. $R$. Mahadeva, G. Walsh, C.D.R. Flower, J.M. Shneerson. (C)ERS Journals Ltd 2000.

ABSTRACT: The pulmonary associations of inflammatory bowel disease (IBD) are poorly characterized. The clinical, physiological and high-resolution computed tomographic thorax characteristics of the lung disease in patients with IBD presenting with respiratory symptoms are described.

Detailed clinical information was obtained and standard pulmonary physiological tests and thorax high-resolution computed tomography performed on 14 patients with ulcerative colitis (UC) and three with Crohn's disease (CD), 10 male, aged 38-83 yrs.

Respiratory symptoms had been present for 2-50 yrs and extraintestinal manifestations were present in three $(\mathbf{1 7 . 6 \%})$. Normal pulmonary physiology (six patients) was associated with the high resolution computed tomographic changes of bronchiectasis, mosaic perfusion and air trapping suggestive of obliterative bronchiolitis and a pattern of centrilobular nodules and branching linear opacities ("tree in bud" appearance) suggestive of either cellular bronchiolitis or bronchiolectasis with mucoid secretions. Bronchiectasis was found in 13 patients (11 UC, 2 CD), 11 had air trapping and five had a "tree in bud" appearance on computed tomography. One patient had a predominantly peripheral reticular pattern at the lung bases similar to that found in cryptogenic fibrosing alveolitis and one patient had a mixed reticular and groundglass pattern in the midzones with a patchy distribution in the central and peripheral portions of the lungs with air trapping. Eleven patients (three with alveolitis) exhibited a clinical and/or physiological response to steroids.

Pulmonary abnormalities in ulcerative colitis and Crohn's disease can present years after the onset of the bowel disease and can affect any part of the lungs. Early recognition is important as they can be strikingly steroid-responsive.

Eur Respir J 2000; 15: 41-18.
*Dept of Chest Medicine, Papworth Hospital, Cambridge CB3 8RE, **Dept of Radiology, Addenbrookes Hospital, Cambridge CB2 2QQ, UK.

Correspondence: R. Mahadeva

Respiratory Medicine Unit

Clinic 2A

Box 40

Addenbrookes Hospital

Hills Road

Cambridge CB2 2QQ UK

Fax: 441223216953

Keywords: Bronchiectasis

bronchiolitis

Crohn's disease

high-resolution computed tomography ulcerative colitis

Received: June 191998

Accepted after revision June 71999
Ulcerative colitis (UC) and Crohn's disease (CD) are associated with a variety of systemic manifestations [1]. UC has been associated with upper airway stenosis [2], tracheobronchitis [3, 4], bronchiectasis [5-10], constrictive bronchiolitis [3], panbronchiolitis [11], necrobiotic nodules [8], lung bullae [12], interstitial lung disease [13, 14], bronchiolitis obliterans organizing pneumonia (BOOP) [15], sarcoidosis [16], pulmonary vasculitis $[17,18]$, pulmonary eosinophilia [8], Wegener's granulomatosis without renal involvement [19] and apical fibrosis [20].

Lung involvement with CD has been less often reported but has been associated with granulomatous oedema of the larynx, trachea and bronchi [21], chronic bronchial suppuration [5] and chronic bronchitis [8], bronchiectasis [9, 22], BOOP [8], pulmonary oedema [23], interstitial lung disease [24], alveolar consolidation [25], granulomatous interstitial involvement [26] and lung infiltrates with peripheral eosinophilia [8].

The presence of subclinical disease in patients without respiratory symptoms was suggested in one study because result of abnormal pulmonary function found in $38 \%$ of UC patients and $54 \%$ of CD patients, significantly greater pro-portions than in a healthy control populations [27].

$\overline{\text { For editorial comments see page } 5}$
Pul-monary function abnormalities include a decrease in gas transfer factor [28-30], an elevated functional residual capacity (FRC) and raised residual volume (RV) during periods of active bowel disease [30-32] and an increased frequency of bronchial hyperresponsiveness [33]. Further-more, alveolar lymphocytosis is evident in bronchoalveolar lavage fluid from CD patients without respiratory symptoms [34].

The chest radiograph is often normal in patients with respiratory symptoms and inflammatory bowel disease (IBD) $[6,8]$ and as a result the radiological characteristics remain poorly characterized. Two studies described the high resolution computed tomographic findings in seven patients (in each study) with IBD who presented with cough and sputum production. However, these reports did not correlate the computed tomographic appearances with symptoms or pulmonary physiology or evaluate air trapping with scans performed during expiration $[9,35]$.

Although respiratory symptoms and physiological and high resolution computed tomographic abnormalities in patients with UC and CD have been described separately, little is known about the associations between these factors. In this study the relationship between the clinical features and the physiological and high resolution computed tomographic abnormalities in a group of patients 
with UC and CD with otherwise unexplained pulmonary disease is described.

\section{Methods}

All of the subjects with CD or UC were identified by one author (J.M. Shneerson) as they presented at the chest clinic with respiratory symptoms between 1981 and 1995. They were all interviewed and their case notes scrutinized for details of their bowel disease. Characteristics recorded included the date of diagnosis, the presence of confirmatory histological results, the extent of the disease on the basis of radiological studies and treatment history, e.g. sulphasalazine, mesalazine or surgery. Features of the pulmonary disease, including presenting symptoms, date of diagnosis, smoking history, the presence of other factors that could account for the clinical features and the response to steroid treatment (an improvement in symptoms (clinical response) or forced expiratory volume in one second (FEV1) and/or forced vital capacity (FVC) of $>200 \mathrm{~mL}$ (physiological response)) were also documented. Symptoms of cough, sputum, wheeze and breathlessness were each scored out of a maximum of $2 ; 0=$ no symptoms, $1=$ intermittent symptoms and $2=$ regular symptoms. The total symptom score (maximum of 8 ) for each patient was derived from the sum of the individual symptom scores.

Each patient underwent standard pulmonary function tests for FEV1, FVC, total lung capacity (TLC), RV and transfer coefficient for carbon monoxide (KCO) measured by means of the single-breath test. The results were compared with those of age- and sex-matched controls [36] and expressed as a percentage of the predicted value. The individual results were classified as normal, restrictive or obstructive. Normal physiology was defined by all measurements being $>70 \%$ pred, a restrictive defect as a reduced ( $<70 \%$ pred) FEV 1 and FVC with an FEV1/FVC ratio of $>70 \%$ pred and an obstructive defect as a reduced FEV1 with a normal $\mathrm{FVC}$ and a low $\mathrm{FEV} 1 / \mathrm{FVC}$ ratio ( $<70 \%$ pred).

Thorax high resolution CT (HRCT) was performed as close as possible in time to the pulmonary function tests, 1996-1997. Images were acquired during inspiration and expiration from lung apices to bases (1-mm collimation, $10-\mathrm{mm}$ interval (inspiration) or $30-\mathrm{mm}$ interval (expiration), $560 \times 560$ matrix, high spatial frequency reconstruction algorithm). Images were reviewed at a window level of -700 and width of 1200 . Abnormalities were characterized by a consensus of two radiologists who were unaware of the patient symptoms and physiological findings. Bronchiectasis was defined as bronchi greater in diameter than the homologous artery together with evidence of a lack of tapering on sequential slices. Bronchiectasis in each lobe including the lingula was graded according to the ratio of the bronchial diameter to that of the adjacent vessel. It was scored as grade 1 when the ratio was $>1$ but $<2$, grade 2 when the ratio was $>2$ but $<3$, and grade 3 when the ratio was $>3$. Thus, each patient had a maximum possible score of 18. Each lobe was also assessed for the presence of centrilobular nodules and branching linear opacities ("tree in bud" appearance) suggesting cellular bronchiolitis [37], or dilated small airways filled with secretions (bronchiolectasis), and for mosaic perfusion with evidence of air trapping during expiration suggesting obliterative bronch- iolitis [38]. The "tree in bud" appearance and air trapping were each scored out of a maximum of 6 (1 point for each lobe involved) for each patient.

The relationship between clinical characteristics (sex, smoking status, colectomy, duration of bowel disease/lung disease), individual symptom scores, the results of the individual pulmonary physiological tests listed above (in $\%$ pred), and the severity of bronchiectasis, the extent of "tree in bud" changes and air trapping on HRCT was assessed by means of bivariate correlation for all patients. The relationship between the clinical characteristics, individual symptom scores, individual physiological test results and extent of "tree in bud" changes and air trapping were also separately analysed by bivariate correlation for the group of patients with bronchiectasis. A p-value $<0.05$ was considered statistically significant.

\section{Results}

Seventeen patients (10 male) aged 38-83 yrs were investigated (table 1). Fourteen had UC and three had CD. Respiratory symptoms had been present for 2-50 yrs and other extraintestinal manifestations were present in three subjects $(17.6 \%$; one seronegative arthropathy, one mixed connective tissue disease, one iridocyclitis and ankylosing spondylitis). In 16 patients, the onset of the bowel disease predated presentation with pulmonary disease (range 1-25 yrs). Exacerbations of UC and pulmonary disease occurred concurrently in two patients.

No patients had active bowel disease at the time of the study and seven patients (six UC) had undergone colectomy for severe disease. Of these, one had a mixed reticular and ground-glass pattern in the midzones with a patchy distribution in the central and peripheral portions of the lungs and air trapping, similar to those appearances seen in extrinsic allergic alveolitis and sarcoidosis. One patient had a peripheral reticular pattern at the lung bases, characteristic of cryptogenic fibrosing alveolitis, and five had bronchiectasis. Four of the seven colectomy patients developed pulmonary symptoms within 2 yrs of their surgery (table 1).

Lung histology results were obtained for two patients, both of whom have previously been reported [13]. One (No. 4) had cellular interstitial inflammation, little collagen formation and extensive cellular desquamation on transbronchial biopsy, which responded completely to corticosteroids. The other (No. 8) had interstitial fibrosis with fibroblasts and chronic inflammatory cells in the alveolar walls. Interestingly, having completely responded to prednisolone therapy, this patient developed new symptoms some years later and HRCT now shows bronchiectasis and air trapping without evidence of interstitial disease.

Seven individuals were never smokers and seven were exsmokers who had stopped smoking prior to the onset of respiratory symptoms and the HRCT scan. It was unlikely that smoking contributed to the pulmonary disease in the three current smokers as one had a minimal intake (No. 10) and the other two (Nos. 6 and 7) had HRCT abnormalities that are not characteristically associated with smoking.

Five patients were taking sulphasalazine at the time of diagnosis of the pulmonary disease, one had mild upper lobe emphysema probably related to smoking and the other 
Table 1. - Patient characteristics

\begin{tabular}{|c|c|c|c|c|c|c|c|c|}
\hline $\begin{array}{l}\text { Patient } \\
\text { No. }\end{array}$ & $\begin{array}{l}\text { Age } \\
\text { yrs }\end{array}$ & Sex & IBD & $\begin{array}{l}\text { Age at IBD } \\
\text { diagnosis yrs }\end{array}$ & $\begin{array}{l}\text { Age at PD } \\
\text { diagnosis yrs }\end{array}$ & $\begin{array}{l}\text { Colectomy } \\
\text { (age yrs) }\end{array}$ & Sulphasalazine & Smoking \\
\hline 1 & 66 & $\mathrm{~F}$ & $\mathrm{CD}$ & 37 & 60 & $\begin{array}{l}\text { Hemicolectomy and terminal } \\
\text { ileal resection }(49)\end{array}$ & No & Never \\
\hline 2 & 70 & M & UC & 26 & 62 & Panproctocolectomy (52) & No & Never \\
\hline 3 & 58 & $\mathrm{M}$ & UC (distal colitis) & 32 & 56 & No & No & Never \\
\hline $4 *$ & 64 & M & $\mathrm{UC}$ & 51 & 50 & Panproctocolectomy (51) & No & Exsmoker \\
\hline 5 & 71 & M & UC (total colitis) & 65 & 67 & No & No & Exsmoker \\
\hline 6 & 76 & $\mathrm{~F}$ & UC (distal colitis) & 50 & 62 & No & $1 \mathrm{~g}$ b.i.d. & Current \\
\hline 7 & 68 & M & UC (distal colitis) & 62 & 65 & No & $500 \mathrm{mg}$ b.i.d. & Current \\
\hline $8^{*}$ & 74 & $\mathrm{M}$ & UC (distal colitis) & 59 & 66 & No & $1 \mathrm{~g}$ b.i.d. & Exsmoker \\
\hline 9 & 81 & M & UC (proctitis) & 67 & 80 & No & No & Exsmoker \\
\hline 10 & 51 & M & UC & 15 & 38 & Panproctocolectomy (40) & No & Current \\
\hline 11 & 76 & M & $\mathrm{CD}$ & 60 & 73 & No & No & Exsmoker \\
\hline 12 & 76 & $\mathrm{~F}$ & UC & 59 & 62 & Panproctocolectomy (64) & $500 \mathrm{mg}$ b.i.d. & Never \\
\hline 13 & 55 & $\mathrm{M}$ & UC (distal colitis) & 32 & 45 & No & $500 \mathrm{mg}$ b.i.d. & Exsmoker \\
\hline 14 & 79 & $\mathrm{M}$ & CD (sigmoid colitis) & 40 & 64 & No & No & Exsmoker \\
\hline 15 & 83 & $\mathrm{~F}$ & $\mathrm{UC}$ & 31 & 35 & Subtotal colectomy (65) & No & Never \\
\hline 16 & 38 & $\mathrm{~F}$ & UC (distal colitis) & 23 & 32 & No & No & Never \\
\hline 17 & 44 & $\mathrm{~F}$ & UC & 29 & 30 & Panproctocolectomy (30) & No & Never \\
\hline
\end{tabular}

*: previously reported [13]. IBD: inflammatory bowel disease; PD: pulmonary disease; F: female; M: male; UC: ulcerative colitis; CD: Crohn's disease.

four had bronchiectasis, two in association with air trapping. No patients on sulphasalazine showed evidence to suggest an alveolitis.

\section{Symptoms}

Breathlessness was a common presenting symptom in patients with all patterns of disease. Sputum production was not present in three of 13 patients with bronchiectasis, and two of these (Nos. 2 and 5) did not have cough at presentation.

Eleven patients (three interstitial disease, eight bronchiectasis and/or "tree in bud" appearances or air trapping) including all of the colectomy patients showed clinical and/ or physiological improvement in response to oral or inhaled corticosteroids (table 2).

\section{Pulmonary function}

The six patients with normal pulmonary physiology all had a combination of bronchiectasis, air trapping and "tree in bud" appearances of varying severity and extent on HRCT (table 2).

The KCO was reduced in four patients, one in association with fibrosis, one with emphysema which was probably related to smoking and the other two with the most extensive and severe bronchiectasis, "tree in bud" appearances and air trapping of all the patients studied. In three patients, the KCO was elevated, including the patient with peripheral lung fibrosis who showed no evidence of a response to bronchodilators to suggest asthma and two patients with grade 1 bronchiectasis.

\section{High resolution computed tomographic abnormalities}

Thirteen $(76 \%)$ patients had bronchiectasis (11 UC, two CD) (table 3). Nine patients showed evidence of air trapping (fig. 1) and five had "tree in bud" changes (fig. 2 ). Bronchiectasis was present alone in only three patients and two patients had lower lobes affected by both bronchiectasis and air trapping. One patient had bronchiectasis in all lobes in association with "tree in bud" changes but no air trapping and three patients had bronchiectasis with air trapping and "tree in bud" appearances.

Characterization of these abnormalities on a lobar basis showed that air trapping occurred with bronchiectasis in four patients and in the absence of bronchiectasis in two, one of whom showed air trapping in all lobes and grade 1 bronchiectasis in only two lobes (No. 13). In only one lobe of one patient did "tree in bud" appearances and air trapping both occur in the absence of bronchiectasis.

Two patients ( 1 and 9) had HRCT changes suggestive of fibrosis. One showed a mixed reticular and ground-glass pattern in the midzones with a patchy distribution in the central and peripheral portions of the lungs and air trapping, and the other a peripheral reticular pattern (figs 3 and 4).

One patient with regular sputum production suggestive of chronic bronchial suppuration had mild emphysema and parenchymal bands suggestive of fibrosis in the left lower lobe, but showed no HRCT evidence of airway disease. The patient with no high resolution computed tomographic abnormalities (No. 4) had had histologically proven alveolitis 14 yrs previously, which had responded completely to treatment with steroids.

The relationship between clinical characteristics, physiological parameters and high resolution computed tomographic features

There was a strong negative correlation between colectomy and smoking $(\mathrm{r}=-0.73, \mathrm{p}=0.004)$ (five of seven were never smokers). There was no significant correlation between smoking status and individual symptoms, pulmonary physiological test results or abnormalities on HRCT. A longer duration of respiratory symptoms was associated 
Table 2. - Patients' respiratory symptom scores, lung function characteristics and steroid responsiveness

\begin{tabular}{|c|c|c|c|c|}
\hline \multirow{2}{*}{$\begin{array}{l}\text { Patient } \\
\text { No. }\end{array}$} & \multirow{2}{*}{$\begin{array}{l}\text { Symptom } \\
\text { score }\end{array}$} & \multirow{2}{*}{$\begin{array}{l}\text { Lung } \\
\text { function }\end{array}$} & \multicolumn{2}{|l|}{ Response to steroids } \\
\hline & & & Clinical & Physiological \\
\hline 1 & 2 & Restrictive & Improvement in breathlessness & NK \\
\hline 2 & 5 & Restrictive & $\begin{array}{l}\text { Improvement in cough and reduced sputum production with } 15 \mathrm{mg} \\
\text { prednisolone daily }\end{array}$ & Yes \\
\hline 3 & 2 & Normal & (6) & No \\
\hline 4 & 2 & Obstructive & $\begin{array}{l}\text { Improved breathlessness after } 2 \text { weeks and resolution of CXR } \\
\text { changes after } 60 \mathrm{mg} \text { prednisolone daily }\end{array}$ & Yes \\
\hline 5 & 2 & Obstructive + restrictive & NK & NK \\
\hline 6 & 4 & Obstructive + restrictive & NK & NK \\
\hline 7 & 4 & Restrictive & NK & NK \\
\hline 8 & 3 & Normal & $\begin{array}{l}\text { Reduced breathless and cough and resolution of CXR changes when } \\
\text { assessed at } 1 \text { month after } 40 \mathrm{mg} \text { prednisolone daily }\end{array}$ & Yes \\
\hline 9 & 3 & Restrictive & NK & NK \\
\hline 10 & 5 & Normal & $\begin{array}{l}\text { Reduced breathlessness, sputum production and wheeze after } 800 \\
\mu \mathrm{g} \text { beclomethasone daily }\end{array}$ & Yes \\
\hline 11 & 7 & Obstructive & Improved wheeze, cough and breathlessness & NK \\
\hline 12 & 5 & Obstructive & Improvement in wheeze and cough when assessed at 1 month & NK \\
\hline 13 & 3 & Normal & NK & NK \\
\hline 14 & 3 & Obstructive & $\begin{array}{l}\text { Reduced breathless and cough when assessed at } 2 \text { months after } \\
\text { treatment with beclomethasone } 800 \mu \mathrm{g} \text { daily }\end{array}$ & No \\
\hline 15 & 7 & Obstructive & $\begin{array}{l}\text { Reduced wheeze, cough and sputum production when assessed at } 1 \\
\text { month after } 30 \mathrm{mg} \text { prednisolone daily }\end{array}$ & Yes \\
\hline 16 & 5 & Normal & $\begin{array}{l}\text { Reduced wheeze and breathlessness when assessed at } 3 \text { months after } \\
\text { beclomethasone } 2 \mathrm{mg} \text { daily }\end{array}$ & Yes \\
\hline 17 & 5 & Normal & Reduced cough and wheeze after beclomethasone $800 \mu \mathrm{g}$ daily & Yes \\
\hline
\end{tabular}

CXR: chest radiographic; NK: not known.

with a significantly higher TLC $(\mathrm{p}=0.013)$ and a higher $\mathrm{RV}$, which just missed significance $(\mathrm{p}=0.052)$, for patients with bronchiectasis, but there was no significant correlation between the severity of bronchiectasis, "tree in bud" appearances or air trapping on HRCT and the duration of respiratory symptoms. Sputum production was significantly

Table 3. - High resolution computed tomographic abnormalities in each patient*

\begin{tabular}{|c|c|c|c|c|c|}
\hline \multirow{2}{*}{$\begin{array}{l}\text { Patient } \\
\text { No. }\end{array}$} & \multicolumn{2}{|c|}{ Bronchiectasis } & \multirow{2}{*}{$\begin{array}{l}\text { "Tree } \\
\text { in bud" }\end{array}$} & \multirow{2}{*}{$\begin{array}{c}\text { Air } \\
\text { trapping }\end{array}$} & \multirow[t]{2}{*}{ Other } \\
\hline & Lobes & Score & & & \\
\hline 1 & 0 & 0 & 0 & 5 & $\begin{array}{c}\text { Bronchocentric } \\
\text { ground-glass } \\
\text { change }\end{array}$ \\
\hline 2 & 5 & 8 & 5 & 0 & \\
\hline 3 & 2 & 3 & 0 & 2 & \\
\hline 4 & 0 & 0 & 0 & 0 & \\
\hline 5 & 2 & 2 & 0 & 1 & \\
\hline 6 & 5 & 5 & 0 & 0 & \\
\hline 7 & 0 & 0 & 0 & 0 & Emphysema \\
\hline 8 & 2 & 2 & 0 & 2 & \\
\hline 9 & 0 & 0 & 0 & 0 & $\begin{array}{l}\text { Peripheral } \\
\text { ground-glass } \\
\text { change }\end{array}$ \\
\hline 10 & 5 & 5 & 0 & 2 & \\
\hline 11 & 6 & 9 & 5 & 6 & \\
\hline 12 & 2 & 2 & 0 & 0 & \\
\hline 13 & 2 & 2 & 0 & 6 & \\
\hline 14 & 2 & 2 & 0 & 0 & Emphysema \\
\hline 15 & 6 & 9 & 6 & 5 & \\
\hline 16 & 4 & 6 & 4 & 5 & \\
\hline 17 & 2 & 3 & 2 & 2 & \\
\hline
\end{tabular}

*: for scoring system, see Methods. associated with more extensive and more severe bronchiectasis (a higher bronchiectasis score) $(\mathrm{r}=0.86, \mathrm{p}<0.001)$, and more extensive "tree in bud" appearances were significantly associated with cough $(\mathrm{r}=0.62, \mathrm{p}=0.024)$.

An increased RV was associated with cough and wheeze ( $p=0.04$ and 0.007 respectively) and with more extensive "tree in bud" changes but not with the extent of air trapping ( $\mathrm{p}=0.01$ and 0.11 respectively). It was also associated with a higher bronchiectasis score, which just missed significance ( $\mathrm{p}=0.057)$. The FEV1, FVC, TLC and KCO were not associated with symptom severity, bronchiectasis, "tree in bud" changes or air trapping.

Although only five patients had "tree in bud" appearances, more extensive changes were associated with more severe and extensive bronchiectasis $(r=0.89, \mathrm{p}<0.001)$. The extent of air trapping was not significantly linked to the extent of "tree in bud" changes $(r=0.471, p=0.104)$ nor with the severity of bronchiectasis $(\mathrm{p}=0.17)$. The $K \mathrm{CO}$ was not associated with the severity of bronchiectasis or the extent of air trapping or "tree in bud" changes.

\section{Discussion}

Despite the known systemic manifestations of IBD [1] and a number of reports linking lung disease and IBD, this association is often overlooked as an extraintestinal manifestation of either UC or CD. The true prevalence of the association remains unknown, and although it was only found in three of 1,400 cases in one study [39], various factors suggest that this figure is an underestimate of the true prevalence of the association. Firstly, clinicians may not consider an association as patients often present with pulmonary symptoms years after the bowel disease 
a)

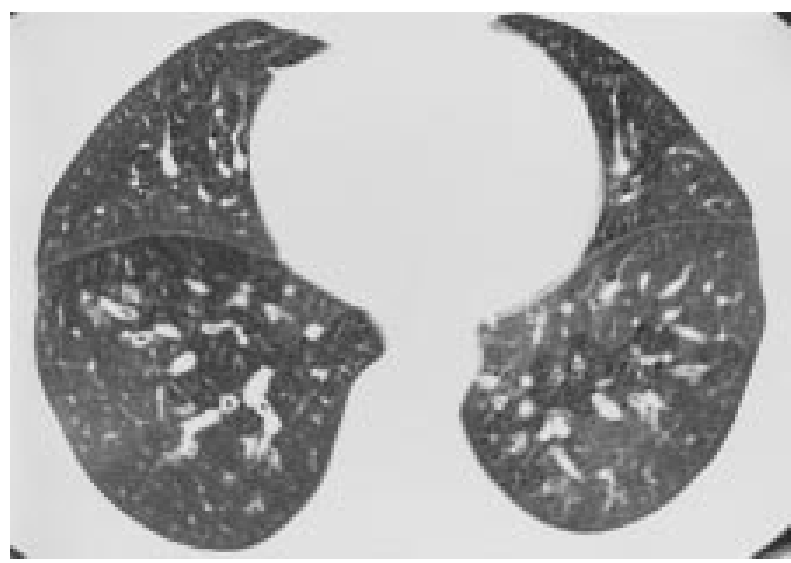

b)

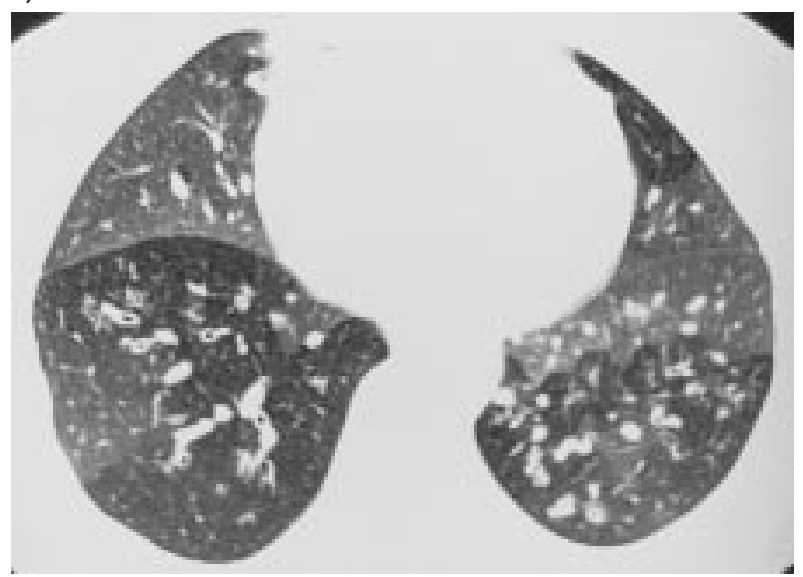

Fig. 1. - High resolution computed tomography. a) At full inspiration minor differences in lung attenuation in both lower lobes and bronchial wall thickening are revealed. b) On expiration, there is evidence of extensive air trapping in keeping with obliterative bronchiolitis.

and after being discharged from gastrointestinal followup [8]. Asymptomatic patients can have abnormal pulmonary function [27-30] and an alveolar lymphocytosis [34] and therefore may not present to a respiratory physician. Patients with bronchiectasis who have a normal chest radiograph $[6,9]$ may also be overlooked. Copious sputum production is often reported as a characteristic feature of the bronchiectasis associated with UC; however, in the present study it was found that the sputum producers were those with the most extensive and severe bronchiectasis and those with bronchiectasis of lesser extent and severity did not expectorate sputum. In addition, patients with normal standard pulmonary function test results can show HRCT evidence of bronchiectasis, "tree in bud" changes and evidence of air trapping.

Compared to other series, the present patients had a lower prevalence of extraintestinal manifestations [8], and there was a lower proportion of females with bronchial disease [6, 7]. In agreement with other series [5-9], colectomy was found to be a risk factor for the development of pulmonary disease, with the development of pulmonary symptoms often occurring close to surgery. It is important to consider whether therapy with sulphasalazine or mesalazine may have been responsible for the pulmonary disease. The most common abnormality des-

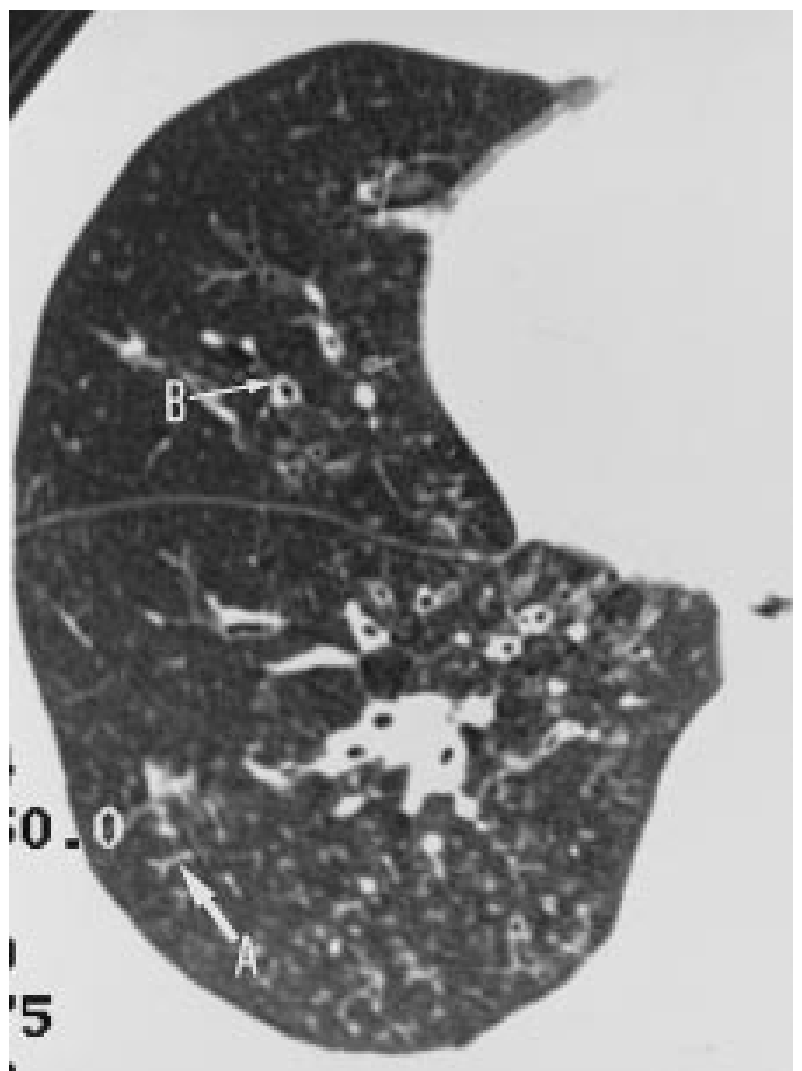

Fig. 2. - High resolution computed tomography revealing micronodules in the right lower lobe. Many have a centrilobular distribution and some are associated with a branching pattern ("tree in bud" changes; A). There is bronchial wall thickening (B).

cribed in association with sulphasalazine therapy is upper lobe peripheral opacities, although lower lobe opacities, eosinophilic pneumonia, interstitial pneumonitis, BOOP and cavitating nodules have also been reported [40-44]. Four of the present patients taking sulphasalazine showed evidence of bronchiectasis and air trapping and one had empysema. None of these patients had eosinophilia,

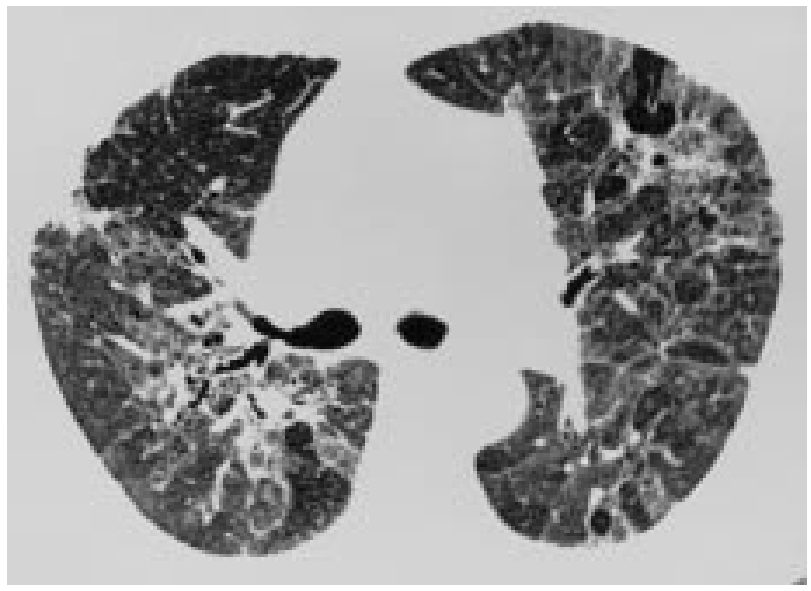

Fig. 3. - High resolution computed tomography showing a mixed reticular and ground-glass pattern in the midzones, with a patchy distribution in the central and peripheral portions of the lung; these changes were seen in association with air trapping on expiratory images. 


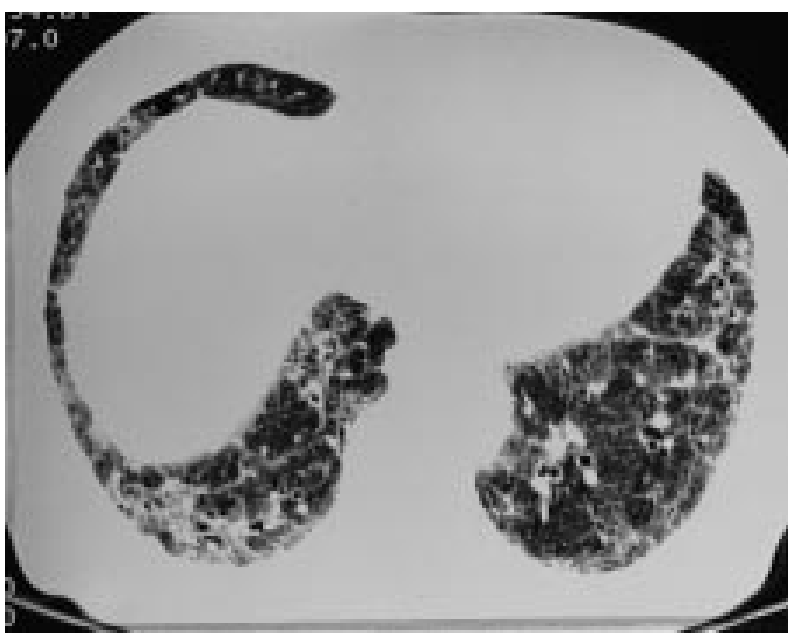

Fig. 4. - High resolution computed tomography of the lungs bases revealing a predominantly reticular pattern with the peripheral distribution characteristic of fibrosing alveolitis.

which is usually present in lung disease caused by sulphasalazine. These features make it unlikely that the drug contributed to the pulmonary abnormalities seen in the patients.

Previous association studies have suggested that smoking is a protective factor for UC $[45,46]$. The present study supports this as smoking was significantly negatively correlated with previous colectomy and hence more severe colitis.

Four patients showed evidence of alveolar disease, three of whom received significant benefit from steroid treatment, with a complete response in two of these. Interestingly, one of these patients (previously reported as case 2 [11]) subsequently developed new respiratory symptoms some years later and was found to have bronchiectasis in association with air trapping. This suggests that the pulmonary disease can recur in different forms in individual patients, something that has not previously been recognized. The other two patients had different patterns of disease, one with HRCT changes similar to those in cryptogenic fibrosing alveolitis and the other with a nonspecific appearance consisting of a mixed reticular and ground-glass pattern.

Although chronic bronchial suppuration [5] and chronic bronchitis [8] have been reported in association with CD, until recently there have been no reports of CD in association with bronchiectasis $[9,22]$. In the present study, two patients were found with this association, one of whom also showed widespread "tree in bud" changes and air trapping. Interestingly, colectomy had not been performed in either.

Previous studies have shown a correlation between HRCT and appearances detection of air trapping and obliterative bronchiolitis [38] and of "tree in bud" appearances with cellular bronchiolitis $[37,38]$, although, in the presence of bronchiectasis, the "tree in bud" appearance may also be due to dilated small airways filled with secretions. Published reports have suggested that the bronchioles are only rarely affected in IBD [8], but in the present study it was found that nine $(53 \%)$ patients showed air trapping and five (29\%) a "tree in bud" appearance. In the two other studies $[9,35]$ to use HRCT, expiratory scans were not performed and air trapping would probably have been underestimated. Whilst air trapping, in keeping with obliterative bronchiolitis, was often present in the current patients with bronchiectasis, it was not associated with the severity or the extent of bronchiectasis. Interestingly, one patient showed extensive air trapping with only minor bronchiectasis in two lobes. "Tree in bud" appearances tended to be associated with extensive and severe bronchiectasis, but were not linked to the extent of air trapping. Air trapping, "tree in bud" changes and bronchiectasis can be present within lobes in individual patients either alone or in combination, suggesting a common pathogenesis for bronchial and bronchiolar injury and a continuum of the tissue response to the same underlying mechanism.

The RV was the only physiological parameter assessed which was associated with symptoms (cough and sputum production) and HRCT abnormalities (bronchiectasis and "tree in bud" appearances). This suggests that it may be the most useful index of disease severity and may be useful in monitoring the disease. This also raises the possibility that the transient hyperinflation noted during attacks of CD [32] and the elevated FRC and RV associated with active IBD $[30,31]$ could reflect bronchial or bronchiolar inflammation with subsequent resolution. Indeed, there were two patients (Nos. 5 and 12) in whom exacerbations of colitis were paralleled by the development of cough and sputum production, one of whom had intrapulmonary shadowing. In both cases, the symptoms and chest radiographic shadowing improved after treatment of the colitis. No correlation was found between the extent of air trapping and physiological measures of RV or the FEV1, which contrasts with previous reports of correlations between the extent of expiratory air trapping and the degree of airflow obstruction in patients with constrictive bronchiolitis and chronic airway disease $[47,48]$. This may be because a semiquantitative scoring system was employed in these studies or due to the insensitivity of standard pulmonary function tests for the detection of small airways disease.

Histologically, the reported case of bronchiolar involvement in UC [3] resembled the bronchiolar changes seen after organ transplantation. The patients' appearances on HRCT were indistinguishable from the radiological features that are often seen in rheumatoid arthritis and graft versus host disease after bone marrow transplantation and after lung transplantation, all of which are thought to have an immunological basis. A large proportion of the patients had pulmonary disease that was responsive to steroids either orally, in the case of alveolar disease, or inhaled or orally or both, in airway disease. These observations suggest that the pulmonary disease in CD and UC has an inflammatory basis. One proposed mechanism for explaining this association is the common embryological derivation of the lungs and gastrointestinal tract from the primitive foregut, and the similarity in the immune systems in the pulmonary and intestinal mucosa [6]. This might explain the development of bronchial disease after colectomy, which implies a shift in the target for the abnormal inflammatory responses.

When assessing the relationship between two diseases, it should be considered that the conditions may have occurred together by chance. Against this are the temporal association, other reports linking the two conditions and the 
lack of any alternative causative factors to explain the pulmonary pathology in these patients. Similarly, with the small number of patients in the present study, it is possible that some of the correlations between clinical characteristics, pulmonary physiological factors and high resolution computed tomographic characteristics could have occurred by chance or that correlations may have been missed.

In summary, pulmonary disease in the form of bronchiectasis, bronchiolitis and interstitial disease of different patterns can occur in patients with both ulcerative colitis and Crohn's disease. A high degree of suspicion is necessary to detect the disease as it may present years after the bowel disease and the patient with airway disease may lack the classical symptoms and yield a normal chest radiograph and physiological test results. Early detection is important as both the alveolar and airway disease often respond well to steroid treatment.

\section{References}

1. Kirsner JB, Shorter RG. Recent developments in nonspecific inflammatory bowel disease. N Engl J Med 1982; 306: 775-785.

2. Rickli H, Fretz C, Hoffman M, Walser A, Knoblauch A. Severe inflammatory upper airway stenosis in ulcerative colitis. Eur Respir J 1994; 7: 1899-1902.

3. Wilcox P, Miller R, Miller G, et al. Airway involvement in ulcerative colitis. Chest 1987; 92: 18-22.

4. Vasishta S, Wood JR, McGinty F. Ulcerative tracheobronchitis years after colectomy for ulcerative colitis. Chest 1994; 106: 1279-1281.

5. Kraft SC, Earle RH, Roesler M, Esterley JR. Unexplained bronchopulmonary disease in patients with inflammatory bowel disease. Arch Intern Med 1976; 136: 454-459.

6. Higgenbottam TW, Cochrane GM, Clark TJH, Turner D, Millis R, Seymour W. Bronchial disease in ulcerative colitis. Thorax 1980; 35: 581-585.

7. Butland RJA, Cole P, Citron KM, Tumer-Warwick M. Chronic bronchial suppuration and inflammatory bowel disease. Q J Med 1981; 197: 63-75.

8. Camus P, Piard F, Ashcroft T, Gal AA, Colby TV. The lung in inflammatory bowel disease. Medicine 1993; 72: 151-183.

9. Spira A, Grossman R, Balter M. Large airway disease associated with inflammatory bowel disease. Chest 1998 ; 113: $1723-1726$.

10. Moles KW, Varghese G, Hayes JR. Pulmonary involvement in ulcerative colitis. Br J Dis Chest 1988; 82: 79-83.

11. Desai SJ, Gephardt GN, Stoller JK. Diffuse panbronchiolitis preceding ulcerative colitis. Chest 1989; 95: $1342-1344$

12. Shneerson JM. Lung bullae, bronchiectasis, and Hashimoto's disease associated with ulcerative colitis treated by colectomy. Thorax 1981; 36: 313-314.

13. Shneerson JM. Steroid-responsive alveolitis associated with ulcerative colitis. Chest 1992; 101: 585-586.

14. McCulloch AJ, McEvoy A, Jackson JD, Jarvis EH. Severe steroid responsive pneumonitis associated with pyoderma gangrenosum and ulcerative colitis. Thorax 1985; 40: 314-315.

15. Swinburn CR, Jackson GJ, Ashcroft T, Morritt GN, Corris PA. Bronchiolitis obliterans organising pneumonia in a patient with ulcerative colitis. Thorax 1988; 43: 735736.

16. Rubenstein I, Baum GL. Association of ulcerative colitis and sarcoidosis? Letter. Chest 1986; 89: 618.
17. Isenberg JI, Goldstein H, Korn AR, Ozelaw RS, Rosen V. Pulmonary vasculitis: an uncommmon complication of ulcerative colitis. N Engl J Med 1968; 279: 1376-1377.

18. Sargent D, Sessions JT, Fairman RP. Pulmonary vasculitis complicating ulcerative colitis. South Med J 1985; 78: 624-625.

19. Kedziora JA, Wolff M, Chang J. Limited form of Wegeners granulomatosis in ulcerative colitis. Am J Roentgenol 1975; 125: 127-133.

20. Meadway J. Ulcerative colitis, colitic spondylitis and associated apical pulmonary fibrosis. Proc Roy Soc Med 1974; 67: 16-17.

21. Lemann M, Messing B, D'Agay F, Modigliani R. Crohn's disease with respiratory involvement. Gut 1987; 28: 1669-1672.

22. Eaton TE, Lambert N, Wells AU. Bronchiectasis following colectomy for Crohn's disease. Thorax 1998; 53: 529531.

23. Bradshaw MJ, Harvey RF, Burns-Cox CJ. Crohn's disease presenting as recurrent pulmonary oedema. BMJ 1981; 283: 1437-1438.

24. Hotermans G, Benard A, Guenanen H, Demarcq-Delerne G, Malart T, Wallaert B. Non-granulomatous interstitial lung disease and Crohn's disease. Eur Respir J 1996; 9: 380-382.

25. Puntis JWL, Tarlow MJ, Raafat F, Weller PH, Booth IW. Crohn's disese of the lung. Arch Dis Child 1990; 65: $1270-1271$.

26. Calder CJ, Lacy D, Raafat F, Weller PH, Booth IW. Crohn's disease with pulmonary involvement in a $3 \mathrm{yr}$ old boy. Gut 1993; 34: 1636-1638.

27. Sommer H, Schmidt M, Gruber KD. Lungenfunktionsstörungen bei Colitis ulcerosa und Morbus Crohn. Dtsch Med Wschr 1986; 111: 812-815.

28. Heatley RV, Thomas P, Prokipchuk EJ, Gauldie J, Sjenjewicz DJ, Bienenstock J. Pulmonary function abnormalities in patients with inflammatory bowel disease. Q J Med 1982; 203: 241-250.

29. Munck A, Murciano D, Pariente R, Cezard JP, Navarro J. Latent pulmonary function abnormalities in children with Crohn's disease. Eur Respir J 1995; 8: 377-380.

30. Neilly JB, Main ANH, McSharry C, Murray J, Russell RI, Moran F. Pulmonary abnormalities in Crohn's disease. Respiratory Medicine 1989; 83: 487-491.

31. Douglas JG, McDonald CF, Leslie MJ, Gillon J, Crompton GK, McHardy GJR. Respiratory impaiment in inflammatory bowel disease: does it vary with disease activity? Respiratory Medicine 1989; 83: 389-394.

32. Pasquis P, Colin R, Denis P, Baptiste P, Galmiche JP, Hecketswener P. Transient pulmonary impaiment in during attacks of Crohn's disease. Respiration 1981; 41: 5659.

33. Louis E, Louis R, Drion V, et al. Increased frequency of bronchial hyperresponsiveness in patients with inflammatory bowel disease. Allergy 1995; 50: 729-733.

34. Bonniere P, Wallaert B, Cortot A, et al. Latent pulmonary involvement in Crohn's disease: biological, functional, bronchoalveolar lavage and scintigraphic studies. Gut 1986; 27: 919-925.

35. Garg K, Lynch DA, Newell JD. Inflammatory airways disease in ulcerative colitis: $\mathrm{CT}$ and high resolution $\mathrm{CT}$ features. J Thorac Imaging 1993; 8: 159-163.

36. Cotes J. Lung function. 1975 Blackwell Scientific Publications.

37. Garg K, Lynch DA, Newell JD, King TE. Proliferative and constrictive bronchiolitis: classification and radiologic features. AJR 1994; 162: 803-808. 
38. Müller NL, Miller RR. Diseases of the bronchioles: CT and histopathologic findings. Radiology 1995; 196: $3-12$.

39. Rodgers BHG, Clark IM, Kirsner JB. The epidemiologic and demographic characteristics of inflammatory bowel disease: analysis of a computerised file of 1400 patients. $J$ Chron Dis 1971; 24: 743-773.

40. Williams T, Eidus L, Thomas P. Fibrosing alveolitis, bronchiolitis obliterans and sulphasalazine therapy. Chest 1982; 81: 766-768.

41. Jones GR, Malone DNS. Sulphasalazine induced lung disease. Thorax 1972; 27: 713-717.

42. Davies D, Macfarlane A. Fibrosing alveolitis and treatment with sulphasalazine. Gut 1974; 15: 185-188.

43. Salerno SM, Ormseth EJ, Roth BJ, Meyer CA, Christensen ED, Dillard ED. Sulfasalazine pulmonary toxicity in ulcerative colitis mimicking clinical features of Wegener's granulomatosis. Chest 1996; 110: 556-559.

44. Reinoso MA, Schroeder KW, Pisani RJ. Lung disease associated with orally administered mesalazine for ulcerative colitis. Chest 1992; 101: 1469-1471.

45. Harries AD, Baird A, Rhodes J. Nonsmoking: a feature in ulcerative colitis. BMJ 1982; 284: 706.

46. Calkins BM. A meta-analysis of the role of smoking in inflammatory bowel disease. Dig Dis Sci 1989; 34: 18411854.

47. Hansell DM. Obliterative bronchiolitis: individual CT signs of small airways disease and functional correlation. Radiology 1997; 203: 721-726.

48. Lucidarme O. Expiratory CT scans for chronic airway disease: correlation with pulmonary function test results. AJR 1998; 170: 301-307. 